\title{
Accumulation of antioxidants and antioxidant activity in tomato, Solanum lycopersicum, are enhanced by the transcription factor SIICE1
}

\author{
Kenji Miura*, Ayaka Sato, Hayato Shiba, Seung Won Kang ${ }^{a}$, Hiroshi Kamada, \\ Hiroshi Ezura \\ Faculty of Life and Environmental Sciences, University of Tsukuba, Tsukuba, Ibaraki 305-8572, Japan \\ *E-mail: kmiura@gene.tsukuba.ac.jp Tel \& Fax: +81-29-853-6401
}

Received October 21, 2011; accepted March 3, 2012 (Edited by T. Aoki)

\begin{abstract}
Antioxidants and antioxidant activity confer important protective effects in plants against the effects of free radicals, which are generated by biotic and abiotic stresses, such as cold. In another study, we identified SIICE1 as a basic helix-loop-helix transcription factor to improve cold tolerance. Here, we demonstrate that SlICE1 plays an important role in the accumulation of antioxidants and in the regulation of antioxidant activity in tomato Solanum lycopersicum. Overexpression of SIICE1 in tomatoes enhanced the accumulation of antioxidants, such as $\beta$-carotene, lycopene, and ascorbic acid, as well as antioxidant activity, measured as the scavenging of 2,2-diphenyl-1-picrylhydazyl (DPPH) free radicals and $\mathrm{O}_{2}^{-}$radicals. Furthermore, the sugar content in SIICE1-overexpressing tomatoes red fruits was higher than that in wild-type red fruits. Metabolite profiling analysis performed by capillary electrophoresis time-of-flight mass spectrometry (CE-TOFMS) revealed that several amino acids and amines were more highly accumulated in SIICE1-overexpressing tomato red fruits compared to those in wild-type tomatoes. These results suggest that SIICE1 plays a role in the regulation of antioxidant activity through the accumulation of several antioxidants.
\end{abstract}

Key words: Antioxidants, antioxidant activity, metabolome, sugar accumulation.

Environmental stresses, including biotic and abiotic stresses, arise from conditions that are unfavorable for the optimal growth and development of organisms (Guy 1999). Low temperatures generally reduce the rates of biological reactions, particularly the rates of carbon dioxide reduction and photorespiration, which leads to limited sinks for the absorbed excitation energy (Allen and Ort 2001). Low temperatures also retard metabolism, delay energy dissipation, and induce the formation of free radicals, resulting in oxidative damage (Beck et al. 2007). Oxidative damage is highly destructive to lipids, nucleic acids, and proteins (Mittler 2002).

Plants have developed complex processes to survive and recover from unfavorable conditions. To tolerate cold stresses, plants develop multiple mechanisms, including the accumulation of cryoprotective molecules and proteins, alterations in membrane lipid composition, and primary and secondary metabolite composition, as well as changes in global gene and protein expression
(Artus et al. 1996; Gilmour et al. 2000; Seki et al. 2001; Cook et al. 2004; Kaplan et al. 2004; Maruyama et al. 2009; Lissarre et al. 2010). For example, temperate plant species promote the synthesis of cryoprotective molecules, such as soluble sugars, sugar alcohols, and low molecular weight nitrogenous compounds (Janská et al. 2010). These compounds act with cold-regulated proteins (CORs), dehydrin proteins, and heat-shock proteins to stabilize membrane phospholipids, membrane proteins, and cytoplasmic proteins for maintenance of hydrophobic interactions and ion homeostasis, and to scavenge reactive oxygen species (ROS) (Janská et al. 2010). In response to cold stress, vacuolar fructans are degraded to generate sugars, including glucose, fructose, and sucrose (Livingston et al. 2006). The activity of antioxidative enzymes, such as superoxide dismutase, glutathione peroxidase, glutathione reductase, and ascorbate peroxidase, as well as the presence of non-enzymatic antioxidants, such as ascorbic acid,

Abbreviations: bHLH, basic helix-loop-helix; CBF, C-repeat binding factor; CE-TOFMS, capillary electrophoresis time-of-flight mass spectrometry; COR, cold-regulated protein; DPPH, 2,2-diphenyl-1-picrylhydazyl; DREB, dehydrin responsive element binding protein; F6P, fructose 6-phosphate; F1,6P, fructose 1,6-bisphosphate; G6P, glucose 6-phosphate; GABA, $\gamma$-aminobutyric acid; GluGABA, $\gamma$-glutamyl-2-aminobutyric acid; GSH, glutathione; ROS, reactive oxygen species.

${ }^{a}$ Present address: Bio Environment Technology Institute, Chung-Ang University, Anseong 456-756, Korea.

This article can be found at http://www.jspcmb.jp/

Published online May 30, 2012 
glutathione, carotenoids, and $\alpha$-tocopherol, increases (Chen and Li 2002). Metabolic profiling analyses demonstrate the accumulation of monosaccharides, disaccharides, trisaccharides, and sugar alcohols, including sucrose, myoinositol, galactinol, and raffinose, is enhanced in cold-exposed Arabidopsis (Cook et al. 2004; Maruyama et al. 2009). These components are also regulated by Arabidopsis AtCBF3/DREB1A (Maruyama et al. 2009). Large amounts of glucose, fructose, glucose6-phosphate (G6P), and fructose-6-phosphate (F6P) are induced by cold treatment in Arabidopsis (Kaplan et al. 2004).

In another study (Miura et al. 2012), we determined that SIICE1 regulates cold signaling and cold tolerance in tomatoes. Overexpression of SIICE1 enhanced plant tolerance to cold stress and expression of cold-responsive genes, such as SlCBF1 and its regulon gene, SlDRCi7 (Miura et al. 2012). In addition, SlICE1 overexpression enhanced accumulation of ascorbate in shoots (Miura et al. 2012). Because ascorbate is an important cold-induced antioxidant that protects ROS and is also increased by overexpression of SIICE1 even under normal conditions, we presumed that other cold-induced metabolites may also be increased in SIICE1-overexpressing plants without cold treatment. We generated SIICE1 overexpression in tomatoes driven by CaMV $35 \mathrm{~S}$ promoter; therefore, accumulation of cold-induced metabolites, including antioxidants, should be observed in all tissues. Among several tomato plant tissues, the fruit is a reservoir of diverse antioxidant molecules, such as ascorbate, carotenoids, and phenolic acids (Breecher 1998). Because of these antioxidants, the fruit is undoubtedly assumed to be a functional food. Here, we report that the overexpression of SIICE1 increases the accumulation of antioxidants, sugars, and amines in tomato fruits. SIICE1-overexpressing tomato red fruits contained a high amount of ascorbate, $\beta$-carotene, and lycopene, and also had enhanced antioxidant activity, which was evaluated by the scavenging of 2,2-diphenyl1-picrylhydazyl (DPPH) free radicals and $\mathrm{O}_{2}^{-}$radicals. These results indicate that SIICE1 plays an important role in the regulation of antioxidant activity and accumulation of antioxidants in tomato fruits.

\section{Materials and methods}

\section{Plant materials and growth conditions}

The tomato (Solanum lycopersicum) cultivar Micro-Tom (accession number TOMJPF00001), provided by the University of Tsukuba through the National BioResource Project of MEXT, Japan, was used as the material for the genetic transformation. Isolation of SIICE1 CDNA and production of SIICE1overexpressing tomatoes are described previously (Miura et al. 2012). Briefly, the SIICE1 coding region was amplified using the primers; SIICE1-KYLX-F (5'-GAAAGCTTATGATAA
CTGGAGTGAAT-3') and SIICE1-KYLX-R (5'-GACTCG AGTTATATCGTCCCCCC-3') and cloned into the pKYLX71 (http://www.uky.edu/ aghunt00/kylx.html) vector. The pKYLX71-SIICE1 vector was transformed into tomatoes with Agrobacterium, as described previously (Sun et al. 2006; Sun et al. 2007). The kanamycin-resistant homozygous tomatoes were selected. The tomato plants were grown at $25^{\circ} \mathrm{C}$ in soil under a 16/8-h (light/dark) photoperiod using fluorescent light. Tomato plants were watered with Hyponex nutrient solution (Hyponex Japan, Osaka, Japan). Tomato red fruits were harvested from 45-52 days after anthesis.

\section{Measurement of brix index and antioxidant metabolites}

Brix (percent soluble solids) was measured using a refractometer (Atago Co., Ltd., Tokyo, Japan) according to the manufacturer's instructions.

Tomato fruit $(0.5 \mathrm{~g})$ was homogenized with a mortar in liquid nitrogen and was extracted with $5 \mathrm{ml}$ of an acetone/ hexane $(4: 6)$ solution. The absorbances of the upper phase at $453,505,645$, and $663 \mathrm{~nm}$ were measured with a DU800 UV/ Vis Spectrophotometer (Beckman Coulter, Inc., Fullerton, CA, USA). The concentrations of $\beta$-carotene and lycopene were calculated as described previously (Nagata and Yamashita 1992).

Tomato fruit $(1.0 \mathrm{~g})$ of the tomato plant was homogenized with a mortar and added to $5 \%(\mathrm{w} / \mathrm{v})$ metaphosphoric acid $(2.0 \mathrm{ml})$. After centrifugation at $12,000 \times \mathbf{g}$ for $3 \mathrm{~min}$, the supernatant was used as a crude extract. Total ascorbic acid content was measured by an Ascorbic Acid Test (Merck, Darmstadt, Germany) using RQ Flex Plus 10 (Merck, Darmstadt, Germany).

\section{Measurement of radical scavenging activity}

Red tomato fruit $(0.5 \mathrm{~g})$ was homogenized with a mortar in liquid nitrogen. The powder was dissolved in $80 \%$ ethanol $(5 \mathrm{ml})$, and further diluted in $80 \%$ ethanol. The same volume of $200 \mu \mathrm{M}$ DPPH was added to the tomato solution. After a 30-min incubation period at room temperature, the absorbance at $517 \mathrm{~nm}$ was measured with a DU800 UV/ Vis Spectrophotometer (Beckman Coulter, Inc., Fullerton, CA, USA). Superoxide anion $\left(\mathrm{O}_{2}^{-}\right)$scavenging activity was measured by the chemiluminescent superoxide anion probe method, using the 2-methyl-6-methoxyphenylethynylimidaz opyrazynone (MPEC) reaction kit (Atto Corp., Osaka, Japan) according to the manufacturer's instructions. $\mathrm{O}_{2}^{-}$was generated using a xanthine/xanthine oxidase system. Light emission was measured with a Compact Luminometer GENE LIGHT GL-200 (Microtec. Nition, Tokyo, Japan).

\section{RNA isolation and quantitative RT-PCR analysis}

Isolation of total RNA and cDNA synthesis was performed as described previously (Miura et al. 2010; Miura et al. 2011b). Quantitative RT-PCR analysis was performed as described previously (Miura and Ohta 2010; Miura et al. 2011c) with 
gene-specific primers; SIP5CS-F (5'-GCTCGAGCTGATGGA AGATTAGCA-3') and SIP5CS-R (5'-CAGTCACCAGAGGCT GAGCTGATG-3') for SlP5CS (Singh et al. 2011), and UBI3-F (5'-CACCAAGCCAAAGAAGATCA- $3^{\prime}$ ) and UBI3-R (5' -TCA GCATTAGGGCACTCCTT-3') for SlUBI3 (Miura et al. 2012).

\section{Measurement of ionic metabolites using a CE- TOFMS system}

Red tomato fruit was weighed and frozen in liquid nitrogen. After the addition of cooled methanol $(3 \mathrm{ml} / \mathrm{mg}$ of tomato tissue) containing $10 \mu \mathrm{M}$ Internal Standard Solution (Human Metabolome Technologies, Inc., Tsuruoka, Japan), frozen tomato tissue was homogenized 4 times with a Shake Master NEO BMS-M10N21 (Biomedical Science, Tokyo, Japan) at $1,500 \mathrm{rpm}$ for $120 \mathrm{~s}$. A $3-\mathrm{ml}$ aliquot of the homogenate was mixed with $3 \mathrm{ml}$ of chloroform and $1.2 \mathrm{ml}$ of ice-cold Milli-Q water. After centrifugation, the separated methanol-water layer was ultrafiltrated using an ultrafiltration tube (UltrafreeMC, UFC3 LCC; Nihon Millipore K.K., Tokyo, Japan) with a molecular weight cut-off of 5,000 Da to remove proteins. The filtrate was evaporated, dissolved in $50 \mu \mathrm{l}$ of Milli-Q water, and analyzed using CE-TOFMS (capillary electrophoresis system equipped with a time-of-flight mass spectrometer).

CE-TOFMS experiments were performed using an Agilent CE-TOFMS (Agilent Technologies, Waldbronn, Germany). Cationic metabolites were analyzed using a fused silica capillary i.d. $50 \mu \mathrm{m} \times 80 \mathrm{~cm}$, with Cation Buffer Solution (Human Metabolome Technologies, Inc., Tsuruoka, Japan) as the electrolyte. The sample was injected at a pressure of $5.0 \mathrm{kPa}$ for $10 \mathrm{~s}$. The applied voltage was set at $27 \mathrm{kV}$. Electrospray ionization-mass spectrometry (ESI-MS) was conducted in the positive ion mode, and the capillary voltage was set at 4,000 V. The spectrometer was scanned from 50 to $1,000 \mathrm{~m} / \mathrm{z}$. Other conditions were the same as those for the cation analysis described previously (Soga and Heiger 2000).

Anionic metabolites were analyzed using a fused silica capillary i.d. $50 \mu \mathrm{m} \times 80 \mathrm{~cm}$, with Anion Buffer Solution (Human Metabolome Technologies, Inc, Tsuruoka, Japan) as the electrolyte. The sample was injected at a pressure of $5.0 \mathrm{kPa}$ for $25 \mathrm{~s}$. The applied voltage was set at $30 \mathrm{kV}$. ESI-MS was conducted in the negative ion mode, and the capillary voltage was set at 3,500 V. The spectrometer was scanned from 50 to $1,000 \mathrm{~m} / \mathrm{z}$. Other conditions were same as those for the cation analysis as described previously (Soga et al. 2007).

Metabolites in the samples were identified by comparison of the migration time and $\mathrm{m} / \mathrm{z}$ ratio with those of authentic standards, in which differences of $\pm 0.5 \mathrm{~min}$ and $\pm 10 \mathrm{ppm}$ were permitted, respectively. Samples were quantified by comparing the peak areas with those of the authentic standards using ChemStation software (Agilent Technologies, Palo Alto, CA, USA). Quantitative values of metabolites are the mean \pm SD for 3 replicates.

\section{Data analysis}

The raw data obtained by CE-TOFMS were processed using the software MasterHands (Human Metabolome Technologies, Inc, Tsuruoka, Japan; Sugimoto et al. 2010). Signal peaks corresponding to isotopomers of 180 compounds (116 cation and 64 anion), including amino acids and the intermediates of the glycolytic system and TCA cycle, were extracted. The migration time of each sample was normalized using those of the internal standards. The resulting relative area values were further normalized based on the sample amounts. The metabolic pathway map was created using the public-domain software, VANTED: Visualization and Analysis of Networks Containing Experimental Data (http://vanted.ipk-gatersleben. de/; Junker et al. 2006).

\section{Results and discussion}

SIICE1 enhances accumulation of antioxidants and antioxidant activity in tomato fruits

When plants suffer from cold stress, they accumulate carbohydrates, amines, and organic acids, including glucose, fructose, sucrose, ascorbate, proline, and glutamine (Cook et al. 2004). Because ICE1 controls several cold-response genes in Arabidopsis (Lee et al. 2005), it is likely that the accumulation of several metabolites would be altered in SIICE1-overexpressing tomato plants. First, we measured Brix (Figure 1A), which shows the concentration percentage of soluble solids, including sugar, salts, protein, and acid, in water solution. SIICE1-overexpressing tomato fruits contain a higher content of soluble solids under non-stressed conditions (Figure 1A).

In plants, abiotic stress stimulates the accumulation of compatible osmolytes and antioxidants to prevent oxidative stresses (Hasegawa et al. 2000). Because SIICE1 regulates cold-regulated genes and accumulation of ascorbic acid in tomato leaves (Miura et al. 2012), it is likely that other antioxidants may be increased in SIICE1overexpressing tomatoes. We investigated the level of antioxidants such as $\beta$-carotene, lycopene, and ascorbic acid in red tomato fruits. The level of antioxidants was increased in transgenic tomatoes, even though the plants were not treated with stress (Figures 1B-D). Because the fruit size of SIICE1-overexpressing plants was relatively smaller than that of the wild-type tomato plants (Miura et al. 2012) and lycopene is favorably accumulated in the fruit's surface (Brandt et al. 2006), it is possible that accumulation of antioxidants could be the result of the smaller fruits of the SIICE1-overexpressing tomato plants; therefore, the concentration of $\beta$-carotene and lycopene in the pericarp and placenta-locular were measured. As reported (Brandt et al. 2006), lycopene was highly accumulated in the pericarp (Figure $1 \mathrm{~F}$ ). Both $\beta$-carotene and lycopene were highly accumulated not only in the pericarp but also in the placenta and locular of SIICE1-overexpressing tomato plants (Figures $1 \mathrm{E}, \mathrm{F})$. Because accumulation of these antioxidants 
A

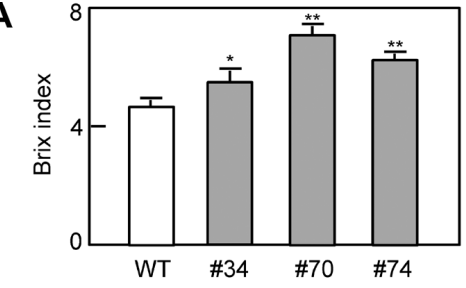

B
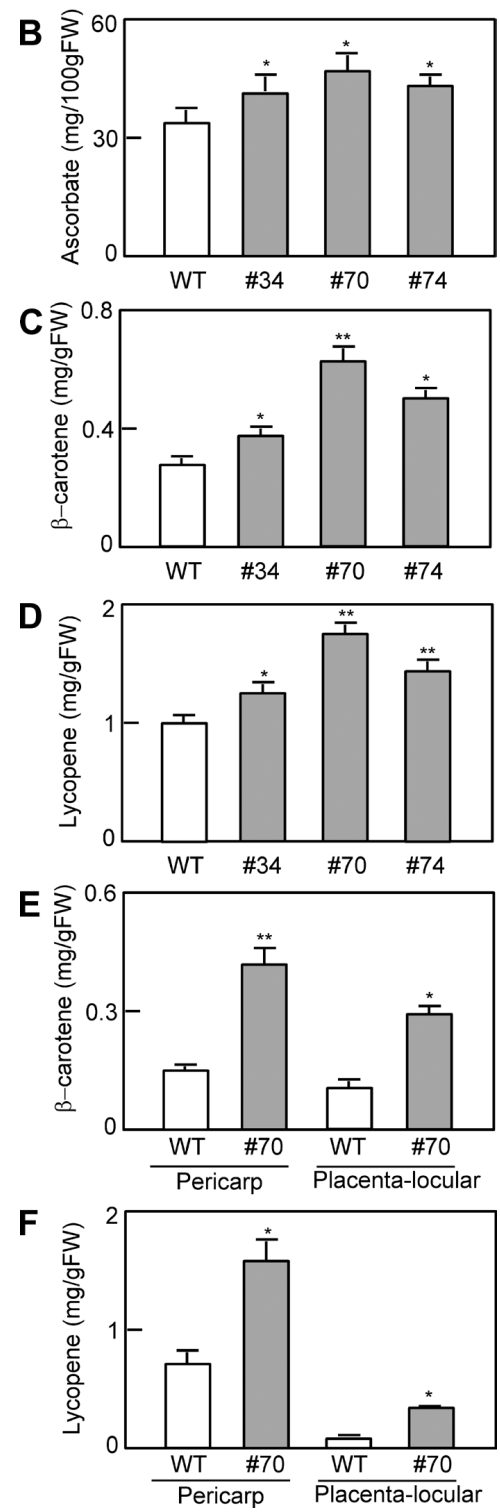

Figure 1. Expression of SIICE1 enhanced the accumulation of antioxidants in red tomato fruits. (A) Brix value was measured. Brix value shows the concentration percentage of soluble solids, comprising sugar, salts, protein, and acid, in water solution. Data are mean \pm SE $(n \geq 10)$. (B) The content of ascorbic acid was increased in SlICE1overexpressing tomato red fruits. Red tomato fruits were ground with metaphosphoric acid and the content of ascorbic acid in the crude extract was measured. (C, D) $\beta$-Carotene and lycopene contents in red fruits were measured. Red tomato fruits were ground into powder and acetone-hexane solution was added. The absorbance was measured and the concentrations of $\beta$-carotene and lycopene were calculated. (E, F) $\beta$-Carotene and lycopene contents in the pericarp and placenta and locular in wild-type and SIICE1-overexpression (\#70) red fruits were measured. Values are average \pm SE $(n \geq 5)$. Asterisks indicate significant difference from wild-type (WT) $(*, p<0.05 ; * *, p<0.01)$. in the placenta and locular in the fruit of the SIICE1overexpressing tomato plants was increased, it is suggested that the accumulation of antioxidants (Figures $1 C, D)$ is not a result of the smaller size of the fruit.

Because antioxidants were accumulated in SIICE1overexpressing tomato red fruit (Figure 1), we posited that SIICE1 enhances antioxidant activity. The antioxidant activity of the fruit was measured by the scavenging of DPPH free radicals and $\mathrm{O}_{2}^{-}$radicals. After dissolving tomato fruit powder in ethanol, DPPH was added and the amounts of free radicals were measured. SIICE1-overexpressing plants exhibited a higher capacity for scavenging DPPH free radicals compared with that of wild-type tomato plants (Figure 2A). Because several radical species are involved in oxidative stress, scavenging $\mathrm{O}_{2}^{-}$radicals produced by the xanthine/ xanthine oxidase system was also investigated. SIICE1overexpressing tomato fruits had a high antioxidant capacity for scavenging $\mathrm{O}_{2}^{-}$radicals (Figure $2 \mathrm{~B}$ ). Carotenoids, such as lycopene and $\beta$-carotene, function as antioxidants (Paiva and Russell 1999). Lycopene is the most powerful carotenoid quencher of singlet oxygen (Di Mascio et al. 1989). The accumulation of these products would contribute to the increase in antioxidant activity (Figures 2A, B).

Increase in the accumulation of sugars and amino acids in SIICE1-overexpressing tomato plants

To prevent ice crystallization during and dehydration low temperatures, plants accumulate osmolytes, such as sugars and proline, and antifreezing proteins (Thomashow 1999); therefore, we investigated metabolite profiles in the red fruits of wild-type and SIICE1overexpressing (\#70) tomato plants. Among several metabolic pathways, the metabolites in glycolysis (Figure 3) are involved in sugar production, and those in the urea cycle and glutamate synthesis pathway (Figure 4) are involved in synthesis of proline and glutathione. These metabolites are important for cold acclimation (Thomashow 1999); therefore, these pathways are focused (Figures 3, 4). Metabolomic analyses (Supplemental Table S1) revealed that the metabolites G6P, F6P, and fructose 1,6-bisphosphate (F1, 6P) were mildly increased in SIICE1-overexpressing plants (Figure 3). These metabolites may contribute to the accumulation of sugars. In SIICE1-overexpressing tomato plants, glutathione (GSH, $\gamma$-Glu-Cys-Gly) and Cys-Gly also accumulated (Figures 3,4). This increased accumulation of GSH is likely to play a role in antioxidant activity because the sulfhydryl group in the cysteine moiety of GSH is thought to be a reducing agent and to be reversibly oxidized and reduced (Foyer and Noctor 2011).

Several amino acids, such as proline, isoleucine, threonine, and glutamate, were also present at higher 

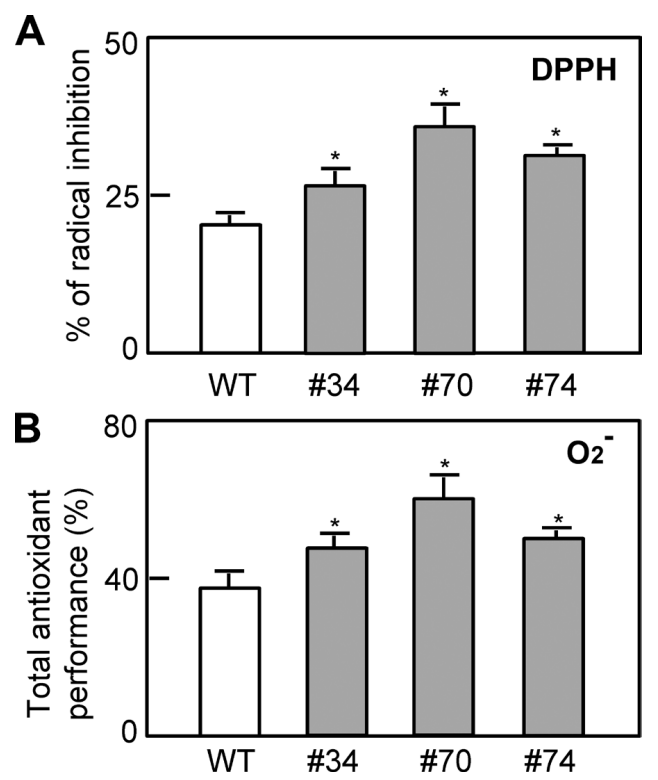

Figure 2. SIICE1-overexpressing tomato red fruits exhibited a high free-radical scavenging capacity. Red fruits were ground into powder and $80 \%$ ethanol was added. DPPH free radicals $(\mathrm{A})$ and $\mathrm{O}_{2}^{-}(\mathrm{B})$ were generated and the extract was added. The ratio of inhibition by tomato red fruit was calculated. Values are average \pm SE $(n \geq 5)$. * Asterisks indicate significantly different from wild type (WT) $(p<0.05)$.

levels in SIICE1-overexpressing tomato red fruits (Table 1). Proline is a well-known compatible osmolyte, which protects membranes and proteins against the adverse effects of inorganic ions and temperature extremes by scavenging ROS at high concentrations (Chen and Dickman 2005; Kaul et al. 2008). Proline also acts as a mediator of osmotic adjustment, a stabilizer of subcellular structures, and a buffer for cellular redox potential (Chen and Murata 2002). $\Delta^{1}$-pyrroline5 -carboxylase synthase (P5CS) is a key regulatory enzyme involved in the biosynthesis of proline. P5CS transcript levels are increased by overexpression of AtCBF3/DREB1A in Arabidopsis (Gilmour et al. 2000) and by cold treatment in rice (Igarashi et al. 1997) and common beans (Chen et al. 2009). SlICE1 also enhanced P5CS expression in tomato red fruits (Figure 4B), leading to the accumulation of proline.

The precursor of proline is glutamate, which was also much increased in SIICE1-overexpressing tomato plants relative to controls (Figure 4A). Accumulation of isoleucine, as well as threonine, a precursor of isoleucine in biosynthetic pathways (Fink et al. 1993), occurred in SIICE1-overexpressing tomatoes (Table 1). Cold stress represses the genes responsible for branched-chain amino acid degradation (Kaplan et al. 2007). Isoleucine is a precursor molecule in branched-chain fatty acid synthesis (Rozgonyi et al. 1990). In Bacillus subtilis, branched-chain fatty acid content increases during cold shock, and isoleucine-deficient strains exhibit cold sensitivity (Klein et al. 1999). Increased branched-chain

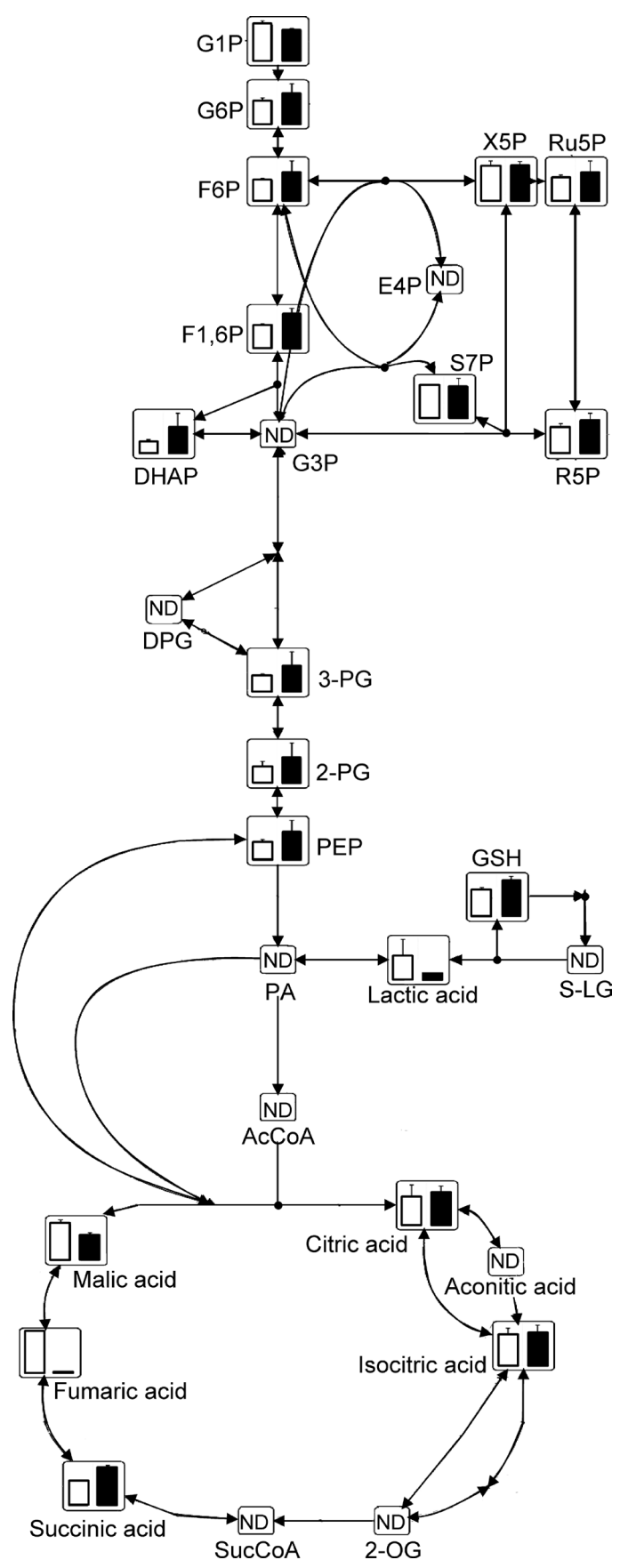

Figure 3. The relative quantitative comparison of glycolysis and TCA cycle-related metabolites in wild-type (white bar) and SIICE1overexpressing (black bar) tomato red fruits using CE-TOFMS. ND indicates "not detected". The full names of each abbreviated metabolite are as follows: 2-OG, 2-oxoglutaric acid; 2-PG, 2-phosphoglycerate; 3-PG, 3-phosphoglycereate; AcCoA, acetyl CoA; DGP, diphosphoglycerate; DHAP, dihydroxyacetone phosphate; E4P, erythrose 4-phosphate; F1,6P, fructose 1,6-diphosphate; F6P, fructose 6-phosphate; G1P, glucose 1-phosphate; G3P, glyceraldehyde3-phosphate; G6P, glucose 6-phosphate; GSH, glutathione; PA, pyruvic acid; PEP, phosphoenolpyruvate; R5P, ribose 5-phosphate; Ru5P, ribulose 5-phosphate; S7P, sedoheptulose 7-phosphate; S-LG, S-lactoylglutathione; SucCoA, succinyl CoA; X5P, xylulose 5-phosphate. 


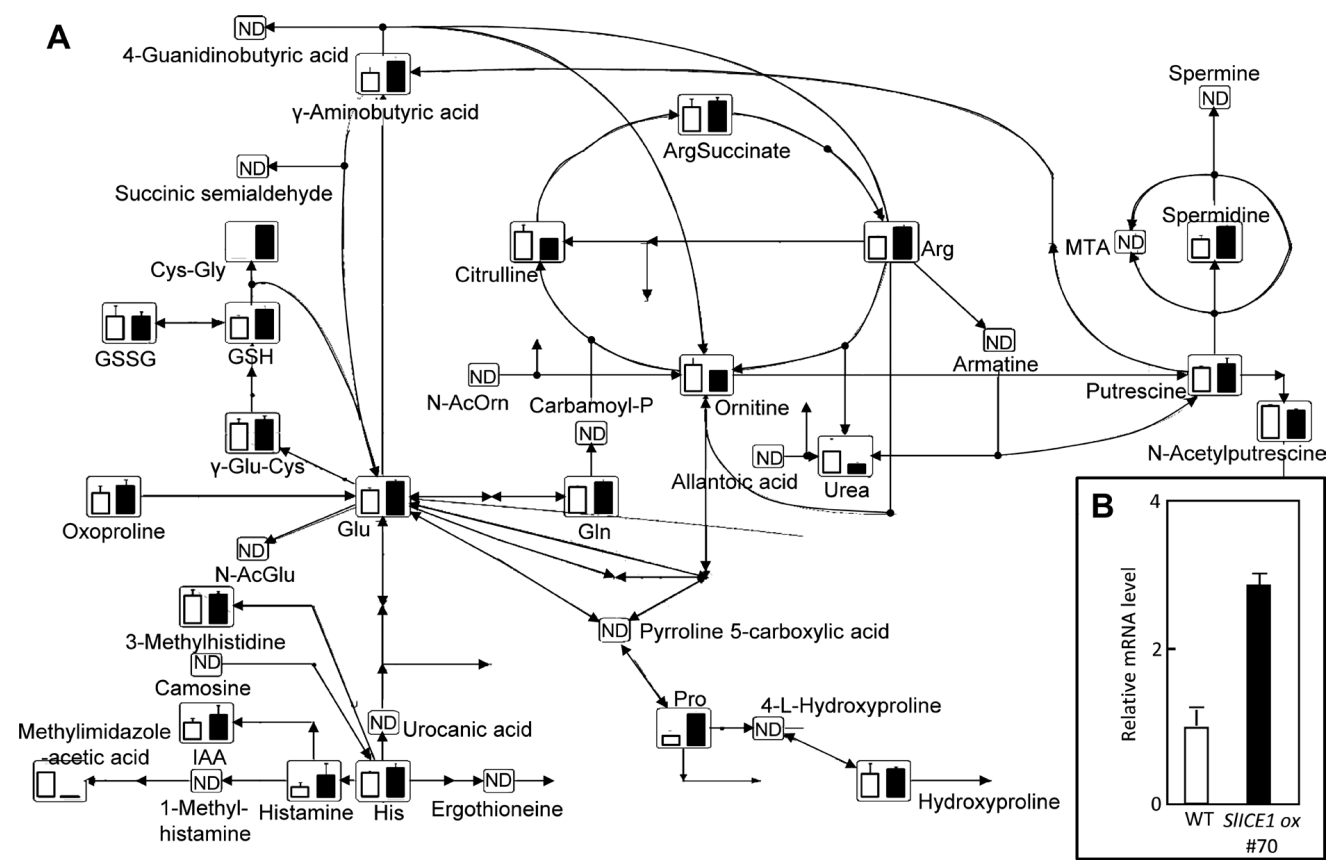

Figure 4. (A) Relative quantitative comparison of urea cycle and amino acid metabolism-related metabolites in wild-type (white bar) and SlICE1overexpressing (black bar) red fruits. ND indicates "not detected". The full names of each abbreviated metabolite are as follows: Arg, arginine; CysGlu, cysteine-glutamate; Gln, glutamine; Glu, glutamate; GSH, glutathione; GSSG, glutathione divalent; His, histidine; IAA, imidazole-4-acetic acid; MTA, 5'-deoxy-5'-methylthioadenosine; N-AcGlu, N-acetylglutamic acid; N-AcOrn, N-acetylornitine; Pro, proline. (B) The relative mRNA transcript level of SlP5CS in red fruits was investigated by quantitative RT-PCR analysis. The data are the means with SD $(n=3)$.

fatty acid content improves cold tolerance in tomatoes (Wang-Pruski and Szalay 2002). Other amino acids, such as arginine, glycine, leucine, and phenylalanine were also mildly increased in SIICE1-overexpressing plants. It is likely that these amino acids are important for cold acclimation and that SIICE1 regulates the accumulation of these metabolites.

On the other hand, the levels of lactic, malic, and fumaric acids in glycolysis and the TCA cycle (Figure 3) as well as ornithine and urea in the urea cycle (Figure $4 \mathrm{~A})$ were decreased in SIICE1 transgenic red tomato fruits. The detailed mechanisms are unknown. The levels of fumaric and malic acids were decreased in SIICE1overexpressing tomatoes, probably because a reduction in the urea cycle led to a reduction in the release of fumaric acid from this cycle (Figures 3,4 ).

\section{SIICE1 promotes accumulation of amines}

In addition to sugars and amino acids, SIICE1 overexpression enhanced the accumulation of several kinds of metabolites (Table 2). Among these metabolites, aliphatic amines, such as isobutylamine, isoamylamine, isopropanolamine, and 3-methoxytyramine were accumulated at high levels in SIICE1 overexpressing red fruits (Table 2). The functional significance of these compounds in the response to cold has not been elucidated.

$\gamma$-Glutamyl-2-aminobutyric acid (GluGABA) is a molecule that consists of L-glutamate conjugated to $\gamma$-aminobutyric acid (GABA). It is the substrate of the enzyme $\gamma$-glutamyl- $\gamma$-aminobutyrate hydrolase, which is involved in the biosynthesis of polyamines (Kuriahara et al. 2005). In barley and wheat, GABA, an aminecontaining metabolite, accumulated to a higher extent during exposure to low temperatures (Mazzucotelli et al. 2006). In SIICE1-overexpressing tomato red fruits, the levels of GABA are also mildly increased (Supplemental Table S1). It is possible that GluGABA has a higher level of function than GABA for cold tolerance in tomatoes.

Seventy genes are predicted as bHLH-type transcription factors in tomato plants (http://planttfdb. cbi.pku.edu.cn:9010/web/index.php?sp=le). Our study demonstrates that SIICE1 plays an important role in the regulation of antioxidant activity and antioxidant accumulation. Cold stress also affects the integrity of plant membranes and their lipid composition through the accumulation of ROS, which causes peroxidation of membrane lipids (Kratsch and Wise 2000; Li et al. 2005). Peroxidation of unsaturated lipids may be the cause of increased membrane rigidity in tropical and subtropical plants exposed to low temperature stresses (Lee et al. 2003); therefore, reduction of ROS is important for survival. Because SIICE1 overexpression enhances antioxidant activity under non-stress condition, tomato fruits should be a more functional food.

SIICE1 is degraded after prolonged treatment under 
Table 1. Quantitative CE-MS metabolomics comparing amino acids in the red fruits of wild-type (WT) and SIICE1-overexpressing (SIICE1-ox) (\#70) tomato plants $(n=3)$.

\begin{tabular}{|c|c|c|c|c|c|}
\hline \multirow{3}{*}{ Amino acids } & \multicolumn{4}{|c|}{ Concentration (nmol/g) } & \multirow{3}{*}{ Ratio } \\
\hline & \multicolumn{2}{|c|}{ WT } & \multicolumn{2}{|c|}{ SIICE1-ox (\#70) } & \\
\hline & Mean & S.D. & Mean & S.D. & \\
\hline Pro & 330 & 167 & 1064 & 117 & $3.2^{*}$ \\
\hline Ile & 285 & 55 & 574 & 136 & $2.0^{*}$ \\
\hline Thr & 430 & 52 & 653 & 42 & $1.5^{*}$ \\
\hline Glu & 3644 & 313 & 4969 & 262 & $1.4^{*}$ \\
\hline Arg & 553 & 13 & 791 & 58 & 1.4 \\
\hline Gly & 356 & 96 & 503 & 98 & 1.4 \\
\hline Leu & 339 & 104 & 562 & 88 & 1.4 \\
\hline Phe & 415 & 75 & 583 & 179 & 1.4 \\
\hline Ser & 1025 & 96 & 1346 & 205 & 1.3 \\
\hline Val & 313 & 45 & 402 & 123 & 1.3 \\
\hline Lys & 925 & 16 & 1187 & 55 & 1.3 \\
\hline Ala & 3551 & 915 & 4505 & 696 & 1.3 \\
\hline Asn & 3506 & 87 & 4401 & 403 & 1.3 \\
\hline Asp & 14689 & 2047 & 18031 & 701 & 1.2 \\
\hline His & 835 & 82 & 1027 & 132 & 1.2 \\
\hline Gln & 10989 & 480 & 13086 & 787 & 1.2 \\
\hline Met & 49 & 7.5 & 52 & 8.7 & 1.1 \\
\hline $\operatorname{Trp}$ & 147 & 53 & 138 & 2.2 & 0.9 \\
\hline Cys & 369 & 128 & 297 & 53 & 0.8 \\
\hline Tyr & 748 & 8.9 & 542 & 43 & 0.7 \\
\hline
\end{tabular}

S.D., standard deviation. ${ }^{*} p<0.05, t$-test.

Table 2. Highly accumulated metabolites in the red fruit of SIICE1-overexpressing (SlICE1-ox) tomato plants (\#70) compared to those in wild-type (WT) tomato plants $(n=3)$.

\begin{tabular}{|c|c|c|c|c|c|}
\hline \multirow{3}{*}{ Metabolites } & \multicolumn{4}{|c|}{ Relative area } & \multirow{3}{*}{ Ratio } \\
\hline & \multicolumn{2}{|c|}{ WT } & \multicolumn{2}{|c|}{ SlICE1-ox (\#70) } & \\
\hline & Mean & S.D. & Mean & S.D. & \\
\hline Cys-Gly & N.D. & N.A. & $1.50 \mathrm{E}-05$ & N.A. & $1<*$ \\
\hline Histidinol & $8.10 \mathrm{E}-06$ & N.A. & $4.90 \mathrm{E}-05$ & $3.50 \mathrm{E}-05$ & $6^{*}$ \\
\hline$\gamma$-Glu-2-aminobutyric acid & $2.90 \mathrm{E}-05$ & $1.30 \mathrm{E}-05$ & $1.50 \mathrm{E}-04$ & $2.00 \mathrm{E}-05$ & $5.1^{*}$ \\
\hline Pro & $1.70 \mathrm{E}-02$ & $8.70 \mathrm{E}-03$ & $5.60 \mathrm{E}-02$ & $6.10 \mathrm{E}-03$ & $3.2^{*}$ \\
\hline Gly-Leu & $3.00 \mathrm{E}-05$ & $1.10 \mathrm{E}-05$ & $7.90 \mathrm{E}-05$ & $3.30 \mathrm{E}-05$ & 2.6 \\
\hline Isobutylamine & $8.90 \mathrm{E}-05$ & $2.30 \mathrm{E}-05$ & $2.30 \mathrm{E}-04$ & $1.40 \mathrm{E}-05$ & $2.6^{*}$ \\
\hline Glycerophosphocholine & $4.70 \mathrm{E}-04$ & $2.90 \mathrm{E}-05$ & $1.20 \mathrm{E}-03$ & $2.20 \mathrm{E}-05$ & $2.6^{*}$ \\
\hline Adenine & $1.90 \mathrm{E}-05$ & $2.90 \mathrm{E}-06$ & $4.50 \mathrm{E}-05$ & $2.50 \mathrm{E}-05$ & 2.3 \\
\hline Isoamylamine & $3.50 \mathrm{E}-04$ & $5.10 \mathrm{E}-05$ & $8.00 \mathrm{E}-04$ & $1.40 \mathrm{E}-05$ & $2.3 *$ \\
\hline $\begin{array}{l}\text { 2-Amino-2- } \\
\text { (hydroxymethyl)-1,3- } \\
\text { propanediol }\end{array}$ & $7.30 \mathrm{E}-05$ & $3.50 \mathrm{E}-05$ & $1.60 \mathrm{E}-04$ & $6.10 \mathrm{E}-05$ & 2.2 \\
\hline $\begin{array}{l}\text { Dihydroxyacetone } \\
\text { phosphate }\end{array}$ & $8.10 \mathrm{E}-05$ & $2.10 \mathrm{E}-05$ & $1.80 \mathrm{E}-04$ & $1.10 \mathrm{E}-04$ & 2.2 \\
\hline Isopropanolamine & $9.00 \mathrm{E}-05$ & 7.30E-06 & $2.00 \mathrm{E}-04$ & $3.50 \mathrm{E}-06$ & $2.2^{*}$ \\
\hline Histamine & $4.10 \mathrm{E}-03$ & $2.10 \mathrm{E}-03$ & $9.00 \mathrm{E}-03$ & $5.20 \mathrm{E}-03$ & 2.2 \\
\hline Glucosamine & $3.10 \mathrm{E}-05$ & $1.40 \mathrm{E}-05$ & $6.50 \mathrm{E}-05$ & $1.50 \mathrm{E}-05$ & 2.1 \\
\hline$N$-Methylproline & $3.60 \mathrm{E}-05$ & $3.80 \mathrm{E}-06$ & $7.60 \mathrm{E}-05$ & $7.00 \mathrm{E}-06$ & $2.1^{*}$ \\
\hline Digalacturonic acid & $1.50 \mathrm{E}-04$ & 7.30E-05 & $3.10 \mathrm{E}-04$ & $4.30 \mathrm{E}-05$ & 2.1 \\
\hline 3-Methoxytyramine & $3.20 \mathrm{E}-05$ & $2.50 \mathrm{E}-05$ & $6.30 \mathrm{E}-05$ & $1.60 \mathrm{E}-06$ & 2.0 \\
\hline$N$-Ethylglycine & $3.40 \mathrm{E}-05$ & N.A. & $6.90 \mathrm{E}-05$ & $8.60 \mathrm{E}-07$ & 2.0 \\
\hline Guanine & $7.00 \mathrm{E}-05$ & $5.00 \mathrm{E}-06$ & $1.40 \mathrm{E}-04$ & $6.70 \mathrm{E}-05$ & 2.0 \\
\hline Ile & $2.20 \mathrm{E}-02$ & $4.30 \mathrm{E}-03$ & $4.50 \mathrm{E}-02$ & $1.10 \mathrm{E}-02$ & $2.0^{*}$ \\
\hline
\end{tabular}

S.D., standard deviation.N.D., not detected.N.A., not applicable. ${ }^{*} p<0.05$, $t$-test. 
low temperatures (Miura et al. 2012), as is AtICE1 through ubiquitylation (Dong et al. 2006). AtICE1 is also regulated by sumoylation at lysine 393 (Miura et al. 2007) and ubiquitylation of AtICE1 is inhibited by substitution of serine 403 to alanine of AtICE1 (Miura et al. 2011a). Because the flanking regions of the sumoylation site (K393) and S403 are highly conserved in SIICE1, it is likely that similar mechanism may function in tomato plants.

In summary, SIICE1 in tomato plants regulates the accumulation of metabolites such as $\beta$-carotene, lycopene, ascorbic acid (Figures $1 \mathrm{~B}-\mathrm{D})$ ), glutathione (Figure 4A), several amino acids (Table 1), and amines (Table 2), and antioxidant activity (Figure 2) as well as cold tolerance (Miura et al. 2012). Therefore, SIICE1 can be utilized to improve the quality of tomato fruits.

\section{Acknowledgements}

We thank Ms. Aya Hiyama, Ms. Rieko Nozawa, and Ms. Risa Osada for technical support. The tomato resources used in this research were provided by the National BioResource Project (NBRP), Japanese Ministry of Education, Culture, Sports, Science and Technology (MEXT), Japan. The production of transgenic tomatoes was supported by the RIKEN Plant Transformation Network. This work was supported, in part, by grants from the Special Coordination Funds for Promoting Science and Technology from MEXT; a Grant-in-Aid for Scientific Research on Innovative Areas from MEXT on 'Environmental Sensing of Plants: Signal Perception, Processing Cellular Responses’ (No. 23120503); the Mishima Kaiun Memorial Foundation; and a Cooperative Research Grant of the Gene Research Center, the University of Tsukuba.

\section{References}

Allen DJ, Ort DR (2001) Impacts of chilling temperatures on photosynthesis in warm-climate plants. Trends Plant Sci 6: 36-42 Artus NN, Uemura M, Steponkus PL, Gilmour SJ, Lin C, Thomashow MF (1996) Constitutive expression of the coldregulated Arabidopsis thaliana COR15a gene affects both chloroplast and protoplast freezing tolerance. Proc Natl Acad Sci USA 93: 13404-13409

Beck EH, Fettig S, Knake C, Hartig K, Bhattarai T (2007) Specific and unspecific responses of plants to cold and drought stress. $J$ Biosci 32: 501-510

Brandt S, Pék Z, Barna É, Lugasi A, Helyes L (2006) Lycopene content and colour of ripening tomatoes as affected by environmental conditions. J Sci Food Agric 86: 568-572

Beecher GR (1998) Nutrient content of tomatoes and tomato products. Proc Soc Exp Biol Med 218: 98-100

Chen C, Dickman MB (2005) Proline suppresses apoptosis in the fungal pathogen Colletotrichum trifolii. Proc Natl Acad Sci USA 102: 3459-3464

Chen JB, Wang SM, Jing RL, Mao XG (2009) Cloning the PvP5CS gene from common bean (Phaseolus vulgaris) and its expression patterns under abiotic stresses. J Plant Physiol 166: 12-19

Chen WP, Li PH(2002) Attenuation of reactive oxygen production during chilling in ABA-treated maize cultured cells. In: Li PH, Palva ET (eds), Plant Cold Hardiness. Kluwer Academic Publishers, Dorderecht, The Netherlands, pp. 223-233
Chen TH, Murata N (2002) Enhancement of tolerance of abiotic stress by metabolic engineering of betaines and other compatible solutes. Curr Opin Plant Biol 5: 250-257

Cook D, Fowler S, Fiehn O, Thomashow MF (2004) A prominent role for the $\mathrm{CBF}$ cold response pathway in configuring the lowtemperature metabolome of Arabidopsis. Proc Natl Acad Sci USA 101: $15243-15248$

Di Mascio P, Kaiser S, Sies H (1989) Lycopene as the most efficient biological carotenoid singlet oxygen quencher. Arch Biochem Biophys 274: 532-538

Dong CH, Agarwal M, Zhang Y, Xie Q, Zhu JK (2006) The negative regulator of plant cold responses, HOS1, is a RING E3 ligase that mediates the ubiquitination and degradation of ICE1. Proc Natl Acad Sci USA 103: 8281-8286

Fink PS (1993) Biosynthesis of branched-chain amino acids. In: Sonenshein AL, Hoch JA, Losick R (eds) Bacillus subtilis and other gram-positive bacteria: biochemistry, physiology, and molecular genetics. Washington D.C.: American Society for Microbiology. pp 307-318.

Foyer CH, Noctor G (2011) Ascorbate and glutathione: the heart of the redox hub. Plant Physiol 155: 2-18

Gilmour SJ, Sebolt AM, Salazar MP, Everard JD, Thomashow MF (2000) Overexpression of the Arabidopsis CBF3 transcriptional activator mimics multiple biochemical changes associated with cold acclimation. Plant Physiol 124: 1854-1865

Guy CL (1999) Molecular responses of plants to cold shock and cold acclimation. J Mol Microbiol Biotechnol 1: 231-242

Hasegawa PM, Bressan RA, Zhu JK, Bohnert HJ (2000) Plant cellular and molecular responses to high salinity. Annu Rev Plant Physiol Plant Mol Biol 51: 463-499

Igarashi Y, Yoshiba Y, Sanada Y, Yamaguchi-Shinozaki K, Wada K, Shinozaki K (1997) Characterization of the gene for delta1pyrroline-5-carboxylate synthetase and correlation between the expression of the gene and salt tolerance in Oryza sativa L. Plant Mol Biol 33: 857-865

Janská A, Marsík P, Zelenková S, Ovesná J (2010) Cold stress and acclimation-what is important for metabolic adjustment? Plant Biol (Stuttg) 12: 395-405

Junker BH, Klukas C, Schreiber F (2006) VANTED: a system for advanced data analysis and visualization in the context of biological networks. BMC Bioinformatics 7: 109

Kaplan F, Kopka J, Haskell DW, Zhao W, Schiller KC, Gatzke N, Sung DY, Guy CL (2004) Exploring the temperature-stress metabolome of Arabidopsis. Plant Physiol 136: 4159-4168

Kaplan F, Kopka J, Sung DY, Zhao W, Popp M, Porat R, Guy CL (2007) Transcript and metabolite profiling during cold acclimation of Arabidopsis reveals an intricate relationship of cold-regulated gene expression with modifications in metabolite content. Plant J 50: 967-981

Kaul S, Sharma SS, Mehta IK (2008) Free radical scavenging potential of L-proline: evidence from in vitro assays. Amino Acids 34: 315-320

Klein W, Weber MH, Marahiel MA (1999) Cold shock response of Bacillus subtilis: isoleucine-dependent switch in the fatty acid branching pattern for membrane adaptation to low temperatures. J Bacteriol 181: 5341-5349

Kratsch HA, Wise RR (2000) The ultrastructure of chilling stress. Plant Cell Environ 23: 337-350

Lee BH, Henderson DA, Zhu JK (2005) The Arabidopsis coldresponsive transcriptome and its regulation by ICE1. Plant Cell 17: $3155-3175$

Lee JT, Prasad V, Yang PT, Wu JF, Ho THD, Charng YY, Chan 
MT (2003) Expression of Arabidopsis CBF1 regulated by an $\mathrm{ABA} /$ stress inducible promoter in transgenic tomato confers stress tolerance without affecting yield. Plant Cell Environ 26: $1181-1190$

Li XG, Bi YP, Zhao SJ, Meng QW, Zou Q, He QW (2005) Cooperation of xanthophyll cycle with water-water cycle in the protection of photosystems 1 and 2 against inactivation during chilling stress under low irradiance. Photosynthetica 43: 261-266

Lissarre M, Ohta M, Sato A, Miura K (2010) Cold-responsive gene regulation during cold acclimation in plants. Plant Signal Behav 5: 948-952

Livingston DP, Premakumar R, Tallury SP (2006) Carbohydrate partitioning between upper and lower regions of the crown in oat and rye during cold acclimation and freezing. Cryobiology 52: 200-208

Maruyama K, Takeda M, Kidokoro S, Yamada K, Sakuma Y, Urano K, Fujita M, Yoshiwara K, Matsukura S, Morishita Y, Sasaki R, Suzuki H, Saito K, Shibata D, Shinozaki K, Yamaguchi-Shinozaki K (2009) Metabolic pathways involved in cold acclimation identified by integrated analysis of metabolites and transcripts regulated by DREB1A and DREB2A. Plant Physiol 150: 1972-1980

Mazzucotelli E, Tartari A, Cattivelli L, Forlani G (2006) Metabolism of $\gamma$-aminobutyric acid during cold acclimation and freezing and its relationship to frost tolerance in barley and wheat. J Exp Bot 57: $3755-3766$

Mittler R (2002) Oxidative stress, antioxidants and stress tolerance. Trends Plant Sci 7: 405-410

Miura K, Jin JB, Lee J, Yoo CY, Stirm V, Miura T, Ashworth EN, Bressan RA, Yun DJ, Hasegawa PM (2007) SIZ1-mediated sumoylation of ICE1 controls CBF3/DREB1A expression and freezing tolerance in Arabidopsis. Plant Cell 19: 1403-1414

Miura K, Lee J, Miura T, Hasegawa PM (2010) SIZ1 controls cell growth and plant development in Arabidopsis through salicylic acid. Plant Cell Physiol 51: 103-113

Miura K, Ohta M (2010) SIZ1, a small ubiquitin-related modifier ligase, controls cold signaling through regulation of salicylic acid accumulation. J Plant Physiol 167: 555-560

Miura K, Ohta M, Nakazawa M, Ono M, Hasegawa PM (2011a) ICE1 Ser403 is necessary for protein stabilization and regulation of cold signaling and tolerance. Plant J 67: 269-279

Miura K, Lee J, Gong Q, Ma S, Jin JB, Yoo CY, Miura T, Sato A, Bohnert HJ, Hasegawa PM (2011b) SIZ1 regulation of phosphate starvation-induced root architecture remodeling involves the control of auxin accumulation. Plant Physiol 155: 1000-1012
Miura K, Sato A, Ohta M, Furukawa J (2011c) Increased tolerance to salt stress in the phosphate-accumulating Arabidopsis mutants siz1 and pho2. Planta 234: 1191-1199

Miura K, Shiba H, Ohta M, Kang SW, Sato A, Yuasa T, Iwaya-Inoue M, Kamada H, Ezura H (2012) SlICE1 encoding a MYC-type transcription factor controls cold tolerance in tomato, Solanum lycopersicum. Plant Biotechnol, 29: 253-260

Nagata M, Yamashita I (1992) Simple method for simultaneous determination of chlorophyll and carotenoids in tomato fruit. $J$ Japan Soc Food Sci Technol 39: 925-928

Paiva SA, Russell RM (1999) $\beta$-carotene and other carotenoids as antioxidants. J Am Coll Nutr 18: 426-433

Rozgonyi F, Hahn H, Labischinski H, Giesbrecht P (1990) A novel labeling procedure of anteiso-fatty acid-containing lipids in staphylococci for investigating the effect of penicillin on lipid release. FEMS Microbiol Lett 59: 11-15

Seki M, Narusaka M, Abe H, Kasuga M, Yamaguchi-Shinozaki K, Carninci P, Hayashizaki Y, Shinozaki K (2001) Monitoring the expression pattern of 1300 Arabidopsis genes under drought and cold stresses by using a full-length cDNA microarray. Plant Cell 13: $61-72$

Soga T, Heiger DN (2000) Amino acid analysis by capillary electrophoresis electrospray ionization mass spectrometry. Anal Chem 72: 1236-1241

Soga T, Ishikawa T, Igarashi S, Sugawara K, Kakazu Y, Tomita M (2007) Analysis of nucleotides by pressure-assisted capillary electrophoresis-mass spectrometry using silanol mask technique. J Chromatogr A 1159: 125-133

Sugimoto M, Hirayama A, Robert M, Abe S, Soga T, Tomita M (2010) Prediction of metabolite identity from accurate mass, migration time prediction and isotopic pattern information in CE-TOFMS data. Electrophoresis 31: 2311-2318

Sun HJ, Uchii S, Watanabe S, Ezura H (2006) A highly efficient transformation protocol for Micro-Tom, a model cultivar for tomato functional genomics. Plant Cell Physiol 47: 426-431

Sun HJ, Kataoka H, Yano M, Ezura H (2007) Genetically stable expression of functional miraculin, a new type of alternative sweetener, in transgenic tomato plants. Plant Biotechnol $J$ 5: 768-777

Thomashow MF (1999) Plant cold acclimation: Freezing tolerance genes and regulatory mechanisms. Annu Rev Plant Physiol Plant Mol Biol 50: 571-599

Wang-Pruski G, Szalay AA(2002) Transfer and expression of the genes of Bacillus branched chain alpha-oxo acid decarboxylase in Lycopersicun esculentum. Electronic J Biotechnol ISSN: 0717-3458 